\title{
Utility of Intraoperative Ultrasound in Neurosurgery
}

\section{Utilidade do ultrassom intraoperatório em neurocirurgia}

\author{
Gustavo Enrique Faria Méndez ${ }^{1}$ César José Roa Chacón ${ }^{1}$ Nafxiel Jesus Brito Núñez ${ }^{1}$ (1) \\ José Ramón Zerpa ${ }^{1}$ \\ ${ }^{1}$ Department of Neurosurgery, Hospital Universitario de Caracas, \\ Caracas, Venezuela \\ Address for correspondence Nafxiel Brito, MD, Department of \\ Neurosurgery, Hospital Universitario de Caracas, Caracas, \\ Arq Bras Neurocir 2021;40(2):e113-e119. \\ Distrito Capital 1053, Venezuela (e-mail: nafxiel@gmail.com).
}

\begin{abstract}
Objective The purpose of the present study is to demonstrate the usefulness of intraoperative ultrasound guidance as a technique for the assessment, in real time, of tumor resection and as a navigation aid during intra-axial brain lesion removal on patients admitted in the Neurosurgical Department at the Hospital Universitario de Caracas, Caracas, Venezuela, in 2018.

Methods A total of 10 patients were enrolled, each with intra-axial brain lesions with no previous neurosurgical procedures and a mean age of 49 years old, ranging from 29 to 59 years old.

Results A male predominance was observed with 7 cases (70\%) over 3 female cases (30\%). Six patients had lesions in the dominant hemisphere. The frontal lobe was the most commonly affected, with 5 cases, followed by the parietal lobe, with 4 cases. After craniotomy, ultrasound evaluation was performed previously to dural opening, during tumor resection and after tumor removal. The mean tumor size in axial, coronal and sagittal views was $3.72 \mathrm{~cm}, 3.08 \mathrm{~cm}$ and $3.00 \mathrm{~cm}$, respectively, previously to dural opening with intraoperative ultrasound. The average tumor depth was $1.73 \mathrm{~cm}$ from the cerebral cortex. The location and removal duration from the beginning of the

\section{Keywords}

- intraoperative ultrasound

- brain tumor

- glioma surgery

Resumo approach (ultrasound usage time) was 83.60 minutes, and the average surgery duration was 201 minutes. Navigation with intraoperative ultrasound served to resect intra-axial tumors more precisely and safely. There was no postoperative complication associated with the surgery in this series of cases.

Conclusions Intraoperative ultrasound guidance for intra-axial subcortical tumor resection is a technique that serves as a surgical and anatomical orientation tool.

Objetivo O objetivo do presente estudo é demonstrar a utilidade da orientação ultrassonográfica intraoperatória como técnica de avaliação, em tempo real, da ressecção tumoral e como auxiliar de navegação na remoção de lesão cerebral intraaxial em pacientes internados no Serviço de Neurocirurgia do Hospital Hospital Universitario de Caracas, Caracas, Venezuela, em 2018.
\end{abstract}

received

August 21, 2020

accepted

DOI https://doi.org/

10.1055/s-0040-1722243. ISSN 0103-5355.

\footnotetext{
(c) 2021. Sociedade Brasileira de Neurocirurgia. All rights reserved. This is an open access article published by Thieme under the terms of the Creative Commons Attribution-NonDerivative-NonCommercial-License, permitting copying and reproduction so long as the original work is given appropriate credit. Contents may not be used for commercial purposes, or adapted, remixed, transformed or built upon. (https://creativecommons.org/ licenses/by-nc-nd/4.0/)

Thieme Revinter Publicações Ltda., Rua do Matoso 170, Rio de Janeiro, RJ, CEP 20270-135, Brazil
} 


\begin{abstract}
Métodos Foram incluídos 10 pacientes, cada um com lesões cerebrais intra-axiais, sem procedimentos neurocirúrgicos prévios e idade média de 49 anos, variando de 29 a 59 anos.

Resultados Foi observada predominância do sexo masculino com 7 casos (70\%) sobre 3 casos do sexo feminino (30\%). Seis pacientes tinham lesões no hemisfério dominante. O lobo frontal foi o mais acometido, com 5 casos, seguido do lobo parietal, com 4 casos. Após a craniotomia, a avaliação ultrassonográfica foi realizada previamente à abertura dural, durante a ressecção do tumor e após a retirada do tumor. O tamanho médio do tumor nas incidências axial, coronal e sagital foi de $3,72 \mathrm{~cm}, 3,08 \mathrm{~cm}$ e $3,00 \mathrm{~cm}$, respectivamente, previamente à abertura dural com ultrassom intraoperatório. A profundidade média do tumor foi de $1,73 \mathrm{~cm}$ do córtex cerebral. O tempo de localização e remoção desde o início da abordagem (tempo de utilização do ultrassom) foi de 83,60 minutos, e o tempo médio de cirurgia foi de 201 minutos. A navegação com ultrassom intraoperatório serviu para ressecar tumores intra-axiais com mais

Palavras-chave

- ultrassom intraoperatório

- tumor cerebral

- cirurgia de glioma precisão e segurança. Não houve complicações pós-operatórias associadas à cirurgia nesta série de casos.

Conclusões A orientação ultrassonográfica intraoperatória para ressecção de tumor subcortical intra-axial é uma técnica que serve como ferramenta de orientação cirúrgica e anatômica.
\end{abstract}

\section{Introduction}

The fundamental steps in any neurosurgical procedure are: spatial orientation, correlation between the preoperative images and intraoperative findings, and determination of the exact anatomical relationships of a tumor with the surrounding normal brain tissue and adjacent vessels. These steps translate into less transgression of the brain and vessels, limiting manipulation to the lesion itself, with the objective of minimizing postsurgical neurological deficits. The real-time correlation between the information provided by preoperative images and topographic transoperative data are not offered by any of the modern neuronavigation imaging techniques. Often, the surgeon faces a normal appearing cerebral cortex and tumor of $<1 \mathrm{~cm}$ in diameter deep in the cortex. ${ }^{1,2}$ Changes in the spatial position of the tumor during and after resection occur related to manipulation, cerebrospinal fluid aspiration, hemorrhage or removal itself. ${ }^{3}$

Intraoperative ultrasound guidance (iUS) is a tool that continues to improve over time in terms of image quality, helping distinguish between pathological and normal tissue with good accuracy and functioning as a real time topographic orientation guide, making it an interesting method to consider for routine use in neurosurgery. It can be used in any operating room, without special instrumentation or arrangements, and can be utilized without the presence of a radiologist or technician; it adds a small amount of time to the surgical procedure and the costs are considerably lower compared with neuronavigation devices and intraoperative magnetic resonance imaging (iMRI). ${ }^{4}$

The known applications of the intraoperative ultrasound guidance are: tumor localization, resection evaluation, identification of surrounding vessels and patency of dural sinuses, brain abscess-guided aspiration, ventriculostomy, among others; however, its use is not routinely standardized. ${ }^{5}$

Guided tumor resection is associated with higher global survival rates. ${ }^{6-9}$ Intraoperative magnetic resonance imaging and neuronavigation are established and well-known techniques, but enormous implementation and maintenance costs and increased surgical duration associated with these techniques indicate that, in the meantime, it is probable that they will not reach most of the neurosurgical units around the world. ${ }^{4-10}$

Intraoperative ultrasound guidance is a technique with lower cost compared with the mentioned iMRI and neuronavigation. An iMRI unit value ranges between US\$ 3 million to US\$ 7 million depending on equipment specifications. The value of an intraoperative computed tomography (CT) scan is between US\$1.5 million and US\$3 million, also depending on equipment specifications plus maintenance fees and licenses associated. The value of an intraoperative ultrasound unit varies between US\$25.000 and US\$55.000. ${ }^{11}$

Ionizing radiation is a concern with the use of intraoperative CT scan unit that is spared with the use of iUS. Postsurgical complications regarding compression of the transductor against the cerebral cortex or infection rates related to iUS are not higher than the one associated by the procedure itself. ${ }^{12}$

In low-grade glioma surgery, the intraoperative differentiation between the tumor and normal cerebral tissue can be quite challenging. ${ }^{13,14}$ The iUS might narrow this gap with the help of real time images. ${ }^{3,6,15}$ The iUS constitutes a complementary tool to neuronavigation images, and it has been proposed for routine use in brain tumor surgery, intra and extra-axial, supra or infratentorial and in intradural spinal tumors. Intraoperative ultrasound guidance differentiates normal from pathologic tissue in 80 to $88 \%$ of the cases, and its use 
increases lesion resection by $55 \%$. Higher rates can be observed if the lesions have heterogeneous properties or cystic areas. ${ }^{16,17}$ Intraoperative ultrasound guidance also provides vascular mapping, particularly arterial, related to the lesion and adjacent tissue, especially when utilized in cerebral arteriovenous malformations. After tumor resection, it is possible to evaluate the presence of residual lesions on the surgical field. ${ }^{16}$

\section{Methods}

A descriptive, case series type of study was performed. ${ }^{18}$ From January to December 2018, 380 surgeries were performed at the Neurosurgery Service of the Hospital Universitario de Caracas, Caracas, Venezuela; of these, 50 were intracerebral tumors, 10 were excluded from family members refusing the procedure, and 30 were emergency surgeries. Other exclusion criteria were previous cranial surgery, deep brain tumors who met the criteria for the use of stereotactic guided biopsy, extraaxial brain tumors, and pregnancy, leaving a sample of 10 patients with the diagnosis of a brain tumor who met the inclusion criteria (a subcortical intra-axial brain tumor diagnosed with magnetic resonance imaging (MRI) and voluntary wish to participate in the study).

A data collection instrument was developed to gather information related to the investigation. Each case was discussed in the weekly medical grand round and was included in the prior authorization of the study by the chairman of the Neurosurgical department and attendants. The preoperative dimensions of the tumor were measure in coronal, sagittal and axial views to compare the MRI with the intraoperative ultrasound findings and to evaluate the percentage of resection.

The surgical procedures were performed in the Hospital Universitario de Caracas with the presence of the usual nursing personnel and using habitual neurosurgical instruments standard in every cranial case.

The ultrasound equipment used for all the cases was: Phillips Ultrasound model Sparq Diagnostic Ultrasound System GMDN 40761 (Phillips Ultrasound Bothell, Bothell, WA, USA). With strict aseptic and antiseptic measures, the tech- nique was applied after an osteoplastic craniotomy of $8 \times 8 \mathrm{~cm}$ minimum for the use of a linear 7 to $11 \mathrm{mHz}$ transducer and a 3 , 5 to $5 \mathrm{mHz}$ sectorial transducer. After the craniotomy, the transducer is placed and the first ultrasound is performed, after the dural opening a second ultrasound is performed, placing the transducer directly on the brain parenchyma. The size of the tumor and the nearby vascular structures with Doppler was taken into account. The distance between the brain surface and the lesion was recorded.

The ultrasound usage, tumor resection and the entire surgical case times were recorded. The ultrasound was also used after apparent complete macroscopic resection and, if remnants of the lesion were found, they were resected if considered safe without damaging surrounding vascular structures or eloquent brain areas.

Bioethical aspects: each patient was properly informed of the procedures and signed the informed consent form. Each of the four bioethical principles was respected. ${ }^{20}$ The present study was evaluated and approved by the bioethical committee of the Hospital Universitario de Caracas.

Statistical analysis: A database was developed with the use of the statistical analysis software IBM SPSS Statistics for Windows, Version 19 in Spanish (IBM Corp., Armonk, NY, USA). Descriptive statistical of absolute frequency was used and mode, median, mean and standard deviation with $95 \%$ confidence intervals (CIs) were registered. The statistical test utilized was the t-student for continuous variables with normal distribution following the Kolmogorov-Smirnov test. The chi-squared test was used for discrete variables. Statistical significance was considered with a $p$-value $<0.05$.

\section{Results}

A total of 10 patients were included in the study, with a mean age of 49 years old, ranging from 29 to 59 years old. The male gender predominated with 7 cases (70\%), and there were 3 females (30\%). Six patients had the lesion in the dominant hemisphere, and the lobe most frequently affected was the frontal, with 5 cases, followed by the parietal lobe with 4 cases. In - Table 1, the description of every case is displayed including gender, age, diagnosis, and location.

Table 1 Demographic characteristics

\begin{tabular}{|l|l|l|l|l|}
\hline Case & Gender & Age (years old) & Diagnosis & Localization (lobe) \\
\hline 1 & M & 33 & Low grade glioma & Parietal - left \\
\hline 2 & M & 46 & High grade glioma (glioblastoma) & Parietal - right \\
\hline 3 & F & 53 & Metastatic adenocarcinoma & Parietal - right \\
\hline 4 & M & 38 & Low grade glioma & Frontal - left \\
\hline 5 & M & 59 & Cavernous angioma & Parietal - right \\
\hline 6 & M & 54 & Metastatic adenocarcinoma & Occipital - right \\
\hline 7 & M & 55 & Metastatic adenocarcinoma & Frontal - left \\
\hline 8 & F & 38 & High grade glioma (glioblastoma) & Frontal - left \\
\hline 9 & M & 56 & Low grade glioma & Frontal - right \\
\hline 10 & F & 29 & High grade glioma (glioblastoma) & Parietal - right \\
\hline
\end{tabular}


Regarding the dimensions of the tumors, it was found that, on average, in the axial, sagittal and coronal views, the sizes were $3.72,3.08$ and $3.00 \mathrm{~cm}$, respectively, similar to the preoperative MRI dimensions. The tumor depth on average was $1.73 \mathrm{~cm}$. The time to locate and resect the lesion with ultrasound (US) was 83.60 minutes, and the average surgical duration was 201 minutes. These dimensions had a significant central tendency measure when the t-student test was applied $(p<0.005$ ) ( - Table 2 ). The cases were operated by a resident of the last year of the postgraduate degree in neurosurgery; a tendency toward lowering surgical duration with each following case was observed. (-Fig. 1).

All patients with the diagnostic of glioblastoma (high grade glioma) had an hypoechoic US pattern. In the case of grade 2 gliomas (low grade glioma), one out of three patients had hypoechoic pattern and two patients had an isoechoic pattern. Metastatic adenocarcinomas had a hyperechoic pattern. One cavernous angioma had a hyperechoic pattern. There was not a statistically significant difference ( - Table 3 ). It was possible to identify the tumor borders before the resection in all of the patients included in the present study; - Fig. 2 shows a case of a metastatic adenocarcinoma in which that gross total resection was made.

\section{Discussion}

The extent of tumor resection has been associated with a significant increase in life expectancy and improvement of

Table 2 Tumor characteristics and surgery duration

\begin{tabular}{|l|l|l|l|l|l|}
\hline Variables & Mean & Standard deviation & \multicolumn{2}{l|}{$\begin{array}{l}\text { 95 Confidence } \\
\text { interval }\end{array}$} & -value* \\
\cline { 3 - 6 } & & & Inferior & Superior \\
\hline Tumor dimensions (cm) & & & & & \\
\hline Axial & & & 2.34 & 5.09 & $<0.001$ \\
\hline Coronal & 3.72 & 1.92 & 2.06 & 4.09 & $<0.001$ \\
\hline Sagittal & 3.08 & 1.42 & 1.40 & 4.60 & 0.002 \\
\hline Tumor depth (cm) & 3.00 & 2.24 & 0.45 & 3.01 & 0.013 \\
\hline Ultrasound usage time (minutes) & 1.73 & 1.78 & 62.01 & 105.19 & $<0.001$ \\
\hline Surgery duration (minutes) & 83.60 & 30.17 & 173.63 & 228.57 & $<0.001$ \\
\hline
\end{tabular}

${ }^{*}$ T- student test.

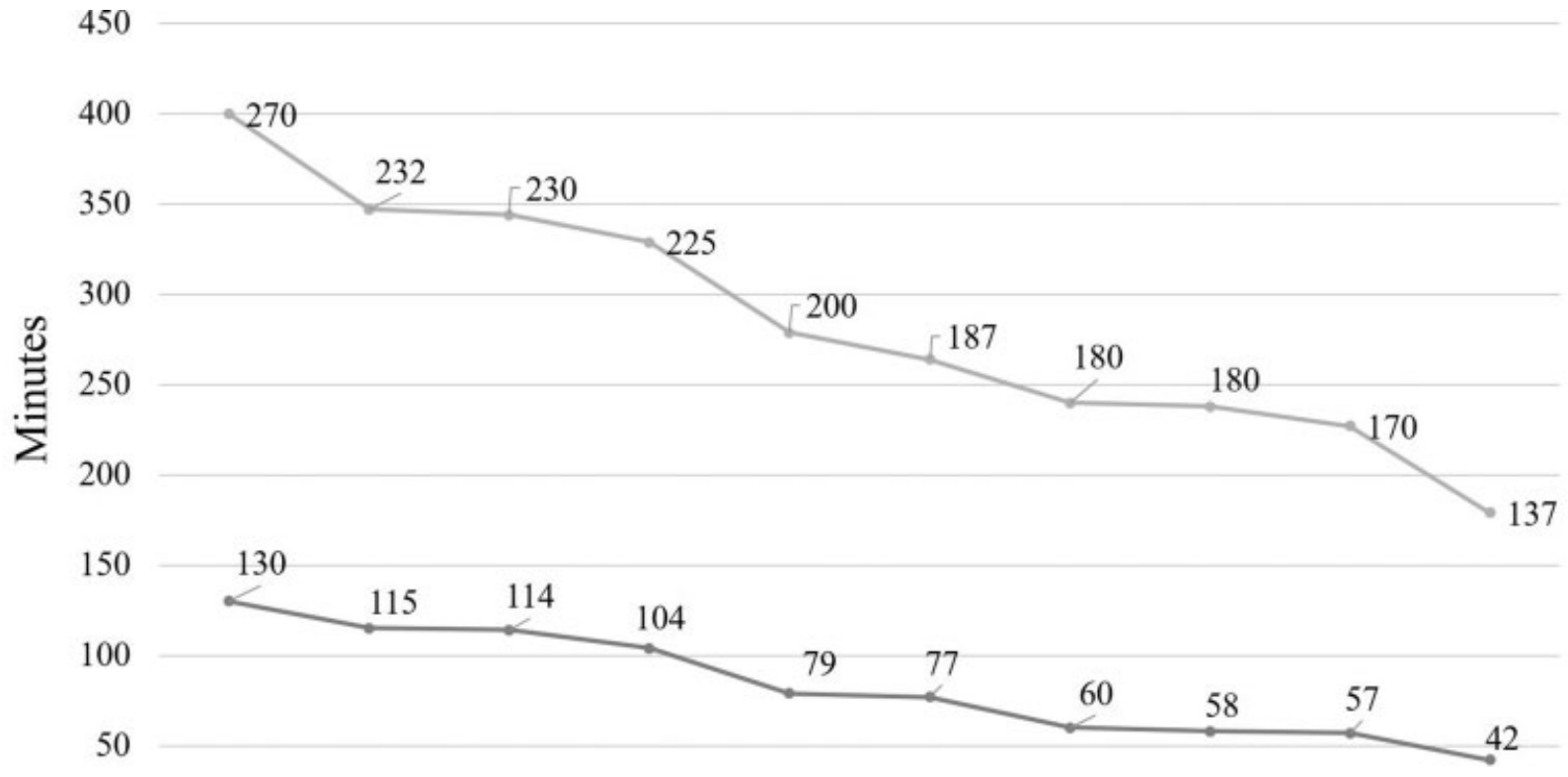

0

Case 1 Case 2 Case 3 Case 4 Case 5 Case 6 Case 7 Case 8 Case 9 Case 10 $\rightarrow$-Ultrasound usage time $\rightarrow$ Surgery duration

Fig. 1 Ultrasound usage time and surgery duration. 
Table 3 Relation between histopathological diagnosis and ultrasound image pattern

\begin{tabular}{|l|l|l|l|l|l|l|l|l|}
\hline \multirow{2}{*}{ Histopathologic Diagnosis } & \multicolumn{4}{l|}{ Ultrasound pattern } & \multicolumn{2}{l|}{ Total } \\
\cline { 2 - 10 } & Hypoechoic & \multicolumn{2}{l|}{ Isoechoic } & Hyperechoic & \multicolumn{2}{l|}{} \\
\cline { 2 - 10 } & $\mathrm{N}$ & $\%$ & $\mathrm{~N}$ & $\%$ & $\mathrm{~N}$ & $\%$ & $\mathrm{~N}$ & $\%$ \\
\hline Glioblastoma (high grade glioma) & 2 & 20.00 & 0 & 0.00 & 0 & 0.00 & 2 & 20.00 \\
\hline Grade II glioma (Low-grade glioma) & 1 & 10.00 & 2 & 20.00 & 0 & 0.00 & 3 & 30.00 \\
\hline Metastatic adenocarcinoma & 1 & 10.00 & 1 & 10.00 & 2 & 20.00 & 4 & 40.00 \\
\hline Cavernous angioma & 0 & 0.00 & 0 & 0.00 & 1 & 10.00 & 1 & 10.00 \\
\hline Total & 4 & 40.00 & 3 & 30.00 & 3 & 30.00 & 10 & 100.00 \\
\hline
\end{tabular}

$p>0.05$; not significant.
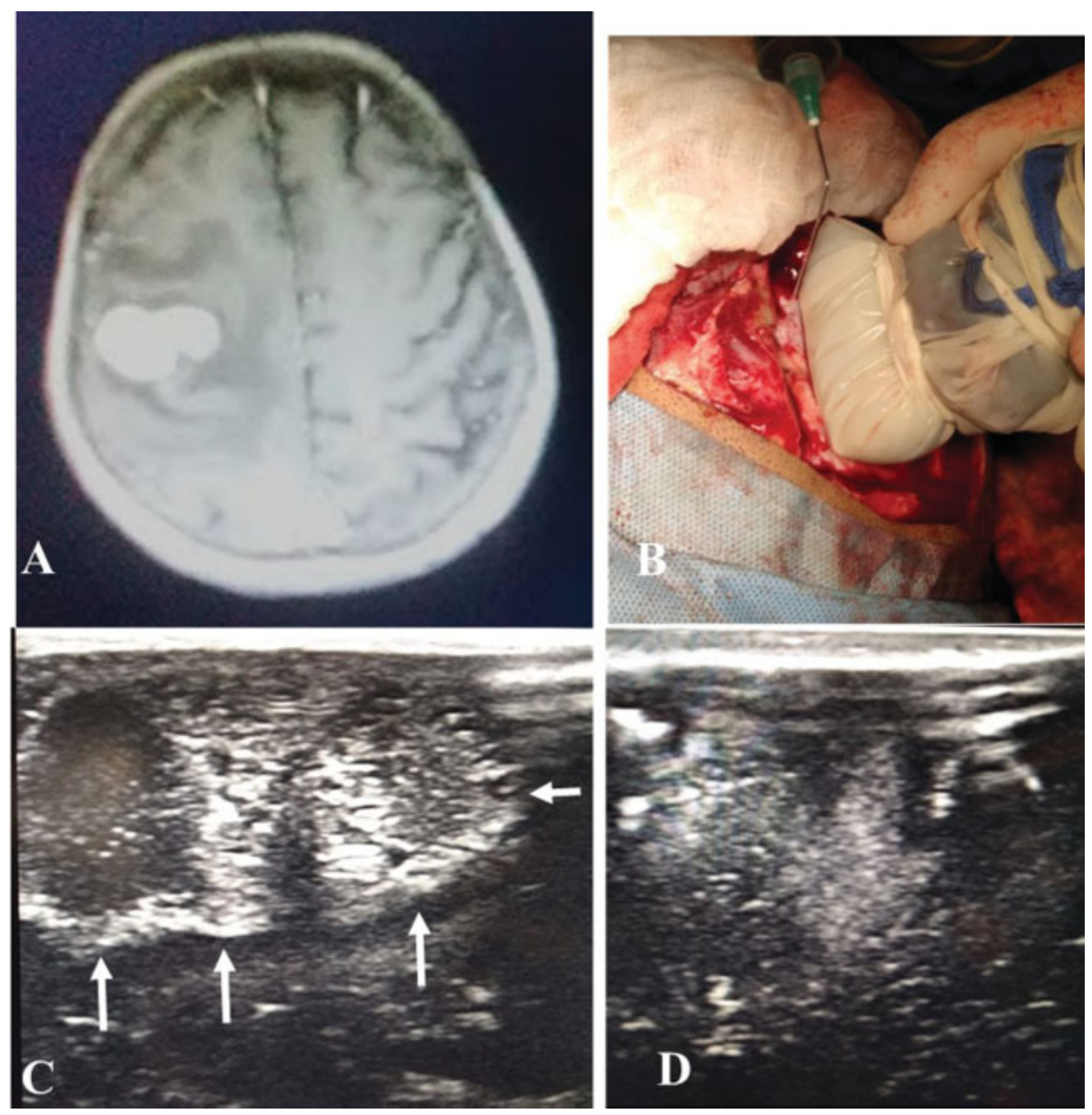

Fig. 2 Case of a metastatic adenocarcinoma in the right parietal lobe (-Fig. 2A), intraoperative image with the transducer placed on the dura (2B), characteristic of the image on ultrasound and delimited with arrows (2C), in the 2D image it is the area of edema after gross total resection.

neurological deficits directly related to the size of the tumor and the level of compression of the surrounding brain tissue, making it interesting that the appropriate use of the navigation technique these objectives, at limitant was that due to institutional difficulties, we do not have magnetic resonance or neuronavigator to properly compare and establish costs, we believe that other characteristics such as: cost / effective- ness, applicability, reliability, reproducibility are possible with this technique, and that training can decrease surgical time. $^{21,22}$

We found that iUS is a very sensitive technique for a brain tumor lesion, secure and precise in the intraoperative trajectory planning toward the lesion and not time consuming compared with other techniques frequently used in our 
department such as stereotactic-guided surgery and neuronavigation. These findings are similar to those of other authors. $^{5,21}$ Intraoperative ultrasound guidance is an effective tool for locating supratentorial brain tumors after the craniotomy, and also an aid for resection control in realtime. ${ }^{4,5,12,15,23-26}$ In our case series, we were able to remove the lesions regardless of the histopathological diagnosis.

Our cases series, the iUS behavior of brain metastasis was demonstrated by a hyperechoic signal, compared with the surrounding normal brain tissue; high-grade gliomas were hypoechoic, and low grade gliomas had an isoechoic signal, which made difficult the differentiation between normal brain tissue as established by Gousias et al. ${ }^{6}$ and Mair et al. ${ }^{3}$ High-grade gliomas and metastasis are hyperechoic compared with the brain with sharp borders, and glioblastomas have cystic cavities hypoechoic in nature (necrosis). Lowgrade gliomas are isoechoic but still distinguishable from surrounding parenchyma.

Intraoperative ultrasound guidance results in less normal brain tissue injury, identification of intralesional or adjacent vascular structures, precise location of subcortical tumors after durotomy independently of the histopathological diagnosis. It is considered a utility method, fast, easy to handle by the neurosurgeon with a short but continuous learning curve that mandates basic knowledge of ultrasonography. Its benefits justify the routine usage for subcortical, intra-axial brain lesions, regardless of the size or histopathological diagnosis.

Preoperative planning of the approach correlating radiological images with craniometric reference points or neuronavigation is mandatory as it affects the final results of the surgery. The craniotomy size should be $\sim 8 \times 8 \mathrm{~cm}$ if a 7 to $11 \mathrm{MHz}$ linear transducer is going to be used. It is also recommended that ultrasonographic interpretation of transoperative images should be included in formal neurosurgical residency programs, in order to stimulate future generations to compare this technique with newer and more advanced techniques to standardize its use in appropriate clinical scenarios.

Limitations related the use of iUS are reverberation in deep seated lesions, ${ }^{27}$ not giving information of tumor location prior to craniotomy, size of craniotomy related to the size of the transducer used. The $6 \times 2 \mathrm{~cm}$ linear 7 to $11 \mathrm{MHz}$ transducer was utilized more frequently, giving higher resolutions and better details with a depth up to $10 \mathrm{~cm}$ from the cerebral surface. Regarding resection control, we found that the postsurgical cavity has to be completely hemostatic without overlying hematomas (hyperechoic), because it interferes with the evaluation of the peripheral tissue and residual tumor. Also, the usage of cottonoids or surgical patties interferes with the postresection evaluation.

There were no complications related to pressure of the transducer against the normal brain tissue measured by postsurgical physical evaluation of each patient, nor increase in surgical site infections.

Neuronavigation has an advantage related to approach and location planning prior to craniotomy or durotomy, but we found that, frequently, the problem in accessing deeply seated lesions is not related to craniotomy location, but after durotomy or corticotomy, and the limitations of this tech- nique after cerebrospinal fluid shifts or partial resection of the tumor are widely known. ${ }^{28-30}$

intraoperative magnetic resonance imaging is a technique with similar results related to the assessment of tumor resection, as stated in many studies, ${ }^{23-26}$ but at a higher cost: requiring complete rebuilding of operating rooms, training of nursing personnel and usage of special surgical instruments; besides, it is not available in our country. This type of technique has indications in resection control of tumors in the diencephalon, brain stem, trans-sphenoidal approaches, among a few others.

Recently, neuronavigation integrated with high resolution tridimensional intraoperative ultrasonography addresses both common problems during tumor resection: location before craniotomy and resection control, respectively. ${ }^{30}$ But studies comparing these combined approaches with the use of each alone are lacking.

\section{Conclusions}

Intraoperative ultrasound guidance for intra-axial subcortical tumor resection is a technique that serves as a surgical and anatomical orientation tool, which correlates with preoperative images and intraoperative findings. We recommend using this technique routinely for intra-axial supratentorial brain tumor resection.

\section{Sources of Financial and Material Support}

The present research did not receive any specific grant from funding agencies in the public, commercial, or notfor-profit sectors.

\section{Conflict of Interests}

The authors have no conflict of interests to declare.

\section{References}

1 Auer LM, Van Velthoven V. Intraoperative Ultrasound Imaging in Neurosurgery, Comparison with CT and MRI. Springered.Berlin, Heidelberg1990

2 Díaz Naranjo YA, Figueredo Méndez JL. Ultrasonido intraoperatorio para detección de tumores intracraneales. Rev Cuba Neurol y Neurocir. 2018;8(01):http://www.revneuro.sld.cu/index.php/neu/ article/view/272/html

3 Mair R, Heald J, Poeata I, Ivanov M. A practical grading system of ultrasonographic visibility for intracerebral lesions. Acta Neurochir (Wien) 2013;155(12):2293-2298. Doi: 10.1007/s00701013-1868-9

4 Eljamel MS, Mahboob SO. The effectiveness and cost-effectiveness of intraoperative imaging in high-grade glioma resection; a comparative review of intraoperative ALA, fluorescein, ultrasound and MRI. Photodiagn Photodyn Ther 2016;16:35-43. Doi: 10.1016/j.pdpdt.2016.07.012

5 Policicchio D, Doda A, Sgaramella E, Ticca S, Veneziani Santonio F, Boccaletti R. Ultrasound-guided brain surgery: echographic visibility of different pathologies and surgical applications in neurosurgical routine. Acta Neurochir (Wien) 2018;160(06):1175-1185. Doi: 10.1007/s00701-018-3532-x

6 Gousias K, Schramm J, Simon M. Extent of resection and survival in supratentorial infiltrative low-grade gliomas: analysis of and adjustment for treatment bias. Acta Neurochir (Wien) 2014;156 (02):327-337. Doi: 10.1007/s00701-013-1945-0 
7 Xia L, Fang C, Chen G, Sun C. Relationship between the extent of resection and the survival of patients with low-grade gliomas: a systematic review and meta-analysis. BMC Cancer 2018;18(01): 48. Doi: 10.1186/s12885-017-3909-x

8 Roelz R, Strohmaier D, Jabbarli R, et al. Residual Tumor Volume as Best Outcome Predictor in Low Grade Glioma - A Nine-Years NearRandomized Survey of Surgery vs. Biopsy. Sci Rep 2016;6:32286. Doi: $10.1038 /$ srep32286

9 Wijnenga MMJ, Mattni T, French PJ, et al. Does early resection of presumed low-grade glioma improve survival? A clinical perspective. J Neurooncol 2017;133(01):137-146. Doi: 10.1007/s11060017-2418-8

10 Senft C, Bink A, Franz K, Vatter H, Gasser T, Seifert V. Intraoperative MRI guidance and extent of resection in glioma surgery: a randomised, controlled trial. Lancet Oncol 2011;12(11):997-1003. Doi: 10.1016/S1470-2045(11)70196-6

11 Ronkainen J, Tervonen O. Cost analysis of an open low-field (0.23T) MRI unit: effect of procedure shares in combined imaging, interventional, and neurosurgical use. Acta Radiol 2006;47(04): 359-365http://www.ncbi.nlm.nih.gov/pubmed/16739694

12 Moiyadi A, Shetty P. Objective assessment of utility of intraoperative ultrasound in resection of central nervous system tumors: A cost-effective tool for intraoperative navigation in neurosurgery. J Neurosci Rural Pract 2011;2(01):4-11. Doi: 10.4103/0976-3147.80077

13 Del Bene M, Perin A, Casali C, et al. Advanced Ultrasound Imaging in Glioma Surgery: Beyond Gray-Scale B-mode. Front Oncol 2018; 8:576. Doi: $10.3389 /$ fonc.2018.00576

14 Petridis AK, Anokhin M, Vavruska J, Mahvash M, Scholz M. The value of intraoperative sonography in low grade glioma surgery. Clin Neurol Neurosurg 2015;131:64-68. Doi: 10.1016/j.clineuro.2015.02.004

15 Moiyadi AV, Shetty P, Degaonkar A. Resection of Pediatric Brain Tumors: Intraoperative Ultrasound Revisited. J Pediatr Neurosci 2017;12(01):19-23. Doi: 10.4103/jpn.JPN_141_16

16 Mena F. ECOGRAFÍA INTRAOPERATORIA EN CIRUGÍA ONCOLÓGICA CEREBRAL Y ESPINAL. Rev Med Clin Las Condes 2017;28(03): 429-436. Doi: 10.1016/j.rmclc.2017.05.009

17 Basauri L, Pinto F, Selman JM. Ecografía intraoperatoria en neurocirugía. Cuad Chil Cirugía 1988;32:109-110

18 Arguedas-Arguedas O. Tipos de diseño en estudios de investigación Biomédica. Acta Med Costarric 2010;52(01):16-18

19 Romero Mares PI. Tecnicas de Muestreo I. Departamento de Probabilidad y Estadística IIMAS UNAM http://www.dpye.iimas.unam. $\mathrm{mx} /$ patricia/muestreo/notas/intro.pdf. Published 2018. Accessed October 1, 2018
20 Kong H. Declaración de helsinki de la amm - principios éticos para las investigaciones médicas en seres humanos. https://www.wma. net/es/policies-post/declaracion-de-helsinki-de-la-amm-principios-eticos-para-las-investigaciones-medicas-en-seres-humanos/. Published 2017. Accessed April 29, 2018

21 Sweeney JF, Smith H, Taplin A, Perloff E, Adamo MA. Efficacy of intraoperative ultrasonography in neurosurgical tumor resection. J Neurosurg Pediatr 2018;21(05):504-510. Doi: 10.3171/2017.11. PEDS17473

22 Wirtz CR, Knauth M, Staubert A, et al. Clinical evaluation and follow-up results for intraoperative magnetic resonance imaging in neurosurgery. Neurosurgery 2000;46(05):1112-1120, discussion 1120-1122. Doi: 10.1097/00006123-200005000-00017

23 Mursch K, Scholz M, Brück W, Behnke-Mursch J. The value of intraoperative ultrasonography during the resection of relapsed irradiated malignant gliomas in the brain. Ultrasonography 2017; 36(01):60-65. Doi: 10.14366/usg.16015

24 Pino MA, Imperato A, Musca I, et al. New Hope in Brain Glioma Surgery: The Role of Intraoperative Ultrasound. A Review. Brain Sci 2018;8(11):202. Doi: 10.3390/brainsci8110202

25 Hammoud MA, Ligon BL, elSouki R, Shi WM, Schomer DF, Sawaya $R$. Use of intraoperative ultrasound for localizing tumors and determining the extent of resection: a comparative study with magnetic resonance imaging. J Neurosurg 1996;84(05):737-741. Doi: $10.3171 /$ jns.1996.84.5.0737

26 Unsgaard G, Gronningsaeter A, Ommedal S, Nagelhus Hernes TA. Brain operations guided by real-time two-dimensional ultrasound: new possibilities as a result of improved image quality. Neurosurgery 2002;51(02):402-411, discussion 411-412. Doi: 10.1227/00006123-200208000-00019

27 López-Hernández F, Hernández-Palazón J, Reus-Pintado MGarrido-Gómez JI, Martínez-Lage JF. Craneotomía guiada por ultrasonografía bidimensional para exéresis de tumor cerebral supratentorial. Neurocirugia (Astur) 2008;19(06):530-536

28 Gerard IJ, Kersten-Oertel M, Petrecca K, Sirhan D, Hall JA, Collins DL. Brain shift in neuronavigation of brain tumors: A review. Med Image Anal 2017;35:403-420. Doi: 10.1016/j.media.2016. 08.007

29 Iversen DH, Wein W, Lindseth F, Unsgård G, Reinertsen I. Automatic Intraoperative Correction of Brain Shift for Accurate Neuronavigation. World Neurosurg 2018;120:e1071-e1078. Doi: 10.1016/j.wneu.2018.09.012

30 Ganau M, Ligarotti GK, Apostolopoulos V. Real-time intraoperative ultrasound in brain surgery: neuronavigation and use of contrast-enhanced image fusion. Quant Imaging Med Surg 2019;9(03):350-358. Doi: 10.21037/qims.2019.03.06 